\title{
Crowdfunding: Finding the Optimal Platform for Funders and Entrepreneurs
}

\section{David Gedda, Billy Nilsson, Zebastian Såthén, and Klaus Solberg Søilen}

\author{
"A compromise is the art of dividing a cake in") \\ such a way that everyone believes that he has \\ got the biggest piece.
}

Ludwig Erhard (1897-1977)

3rd Chancellor of West Germany

\begin{abstract}
As a steadily expanding source of venture capital, crowdfunding has become an alternative to traditional funding sources, such as banks and financial investors. The phenomenon of crowdfunding is represented by a growing number of Internet sites, here called crowdfunding platforms, devoted to the service. In this article, we investigate crowdfunding and their payout models, which are standard components on crowdfunding platforms. We consider the perspectives of both entrepreneurs and funders to determine the most attractive combination of models found on crowdfunding platforms. Our findings indicate that the most popular crowdfunding platforms, at the time of this study, reflect the preferences of entrepreneurs. The funders' favoured crowdfunding model, which we call the equity model, is not currently found, in combination with the often-grouped, non-financial crowdfunding models of pre-order, sponsoring, or reward, on any of the top platforms. Thus, the research identifies a new market for crowdfunding platforms.
\end{abstract}

\section{Introduction}

Firms in the start-up phase are often looking to attract external financing. However, traditional sources of funding such as banks and investors are of limited help when it comes to lending or investing in micro-businesses and small businesses (Belleflamme, Lambert \& Schwienbacher, 2014). Small entrepreneurial firms have sought new ways to secure financing without having to deal with traditional sources (Mollick, 2013), given that, in many cases, the personal resources of would-be entrepreneurs plus any funding they acquire from friends and relatives is not enough to start a firm, and this is a reason that many ideas never become reality (Bradford, 2011). Thus, many entrepreneurs try new financing methods such as crowdfunding (Mollick, 2013). This financing problem sparked the now-booming crowdfunding movement (Belleflamme et al., 2014).

Crowdfunding is defined as "financing projects or businesses with small contributions from large numbers" (Collins \& Pierrakis, 2012). Crowdfunding represents a unique category of fundraising, building on inspiration from concepts such as micro-financing and crowd- sourcing, and is now represented by a growing number of Internet sites devoted to the service. This concept has also opened the gates for people to fund larger-scale projects. All crowdfunding models are based on the principle that people invest funds in a project and expects a successful outcome. The funders' goals are heterogeneous and differ from services and products (Mollick, 2013). It is hard to tell when the idea of crowdfunding started, but we can find many examples of it in history. For example, the composers Mozart and Beethoven used a subscription system to finance compositions and concerts (Hemer, 2011). A more recent example is how US President Barack Obama used a webbased crowdfunding platform to receive numerous small donations during his 2008 presidential campaign (Hemer, 2011). Crowdfunding on the Internet can be designed in different ways, but an understanding of the entrepreneur's choices of crowdfunding models and what motivates the funder is a very important aspect (Belleflamme, Lambert \& Schwienbacher, 2013).

In this article, we describe our work towards developing a universal categorization of the different crowdfunding models. Based on prior research, we suggest a frame- 


\title{
Crowdfunding: Finding the Optimal Platform for Funders and Entrepreneurs
}

\author{
David Gedda, Billy Nilsson, Zebastian Såthén, and Klaus Solberg Søilen
}

work that covers all the existing crowdfunding models and relates them to the 10 most used crowdfunding platforms. We seek to fill a key gap in the literature by determining what entrepreneurs and funders consider as the optimal combination of crowdfunding models on a platform. An optimal combination would benefit both funders and entrepreneurs, and would help entrepreneurs more effectively fund their projects by tailoring their funding requests to the needs of potential funders.

We are aware that funders may be heterogenous from case to case (Mollick, 2013), but we want to propose a generic combination. The aim of the study is to find this optimal combination of crowdfunding models and payout models, regardless of product or service. That is a compromise between what both funders and entrepreneurs perceive as the most suitable combination of crowdfunding models. We also want to relate this optimal combination to an existing crowdfunding platform or suggest a new one that ought to exist based on identified needs. We deem this study relevant because existing universal definitions of the different crowdfunding models (Tomczak \& Brem, 2013), have also failed to mention all existing crowdfunding models. Ultimately, we ask the following question: is there an optimal model for crowdfunding platforms?

\section{Definitions and Literature Review}

Universal definitions of crowdfunding and related terms would benefit any research in this field, although such universal definitions unfortunately do not yet exist (Tomczak \& Brem, 2013). In this article, we define crowdfunding and related concepts as follows:

- Crowdfunding: A way for entrepreneurs to fund their "projects or businesses with small contributions from large numbers" (Collins \& Pierrakis, 2012). This could be done either online or by physical interactions.

- Crowdfunding model: A way of crowdfunding a project that defines what will be invested, loaned, or donated by funders, and what the funders receive in return

- Payout model: Rules regulating how, when, and if a crowdfunding platform transfers funds to the entrepreneur

- Funder: An individual that funds a project via crowdfunding

- Entrepreneur: The individual looking for investors for their project
- Crowdfunding platform: A website dedicated to raising funds via crowdfunding. Such platforms typically make money by adding a fee to the amount funded.

\section{Crowdfunding models}

Tech (2014) summarized the approaches to categorizing crowdfunding models taken in four articles. The four articles did reveal several different crowdfunding models, but the problem posed by Tech (2014) is that different researchers tend to define the same crowdfunding model with different terms. The problem with the lacking of universal definitions for crowdfunding models are that researchers, entrepreneurs, and funders may talk about the same model in different terms without realizing it (Tech, 2014). Thus, through this article, we seek to combine existing research to define universal terms.

Based on research by Hemer (2011), Bradford (2012), Collins and Pierrakis (2012) and Belleflamme and colleagues (2014), we define seven different crowdfunding models:

1. Donation = Funding a project without any expectation of return. When comparing the costs of different sources of capital, donation is by far the cheapest, because the entrepreneur does not incur a cost (Belleflamme et al., 2014) other than the fee charged by the crowdfunding platform.

2. Reward $=$ Funding a project and gaining a reward that is not the actual product or service (e.g., a branded key chain or t-shirt)

3. Sponsorship = Funding a project and in return for a publicly visible connection to the project

4. Pre-order $=$ Funding a project by pre-ordering the actual product or service

5. Lending with interest $=$ Funding a project by lending money to the entrepreneur in return for interest

6. Lending without interest $=$ Funding a project by lending money to the entrepreneur without interest

7. Equity = Funding a project by buying equity in the firm (e.g., pure investment, profit sharing, or any other form of equity return) The progress of this crowdfunding model has been slower than expected, mainly due to regulations (Harrison, 2013). 


\section{Crowdfunding: Finding the Optimal Platform for Funders and Entrepreneurs}

\section{David Gedda, Billy Nilsson, Zebastian Såthén, and Klaus Solberg Søilen}

Based on these seven models, we developed a framework with three categories: no reward, financial, and non-financial rewards (Figure 1).

\section{Payout models}

At the time of this study, crowdfunding platforms mostly use four different payout models for determining how and if a project is successfully funded and how and when the money will be transferred to the entrepreneur. The one thing the four models have in common is that the platform and the funder agree on a pre-determined amount of money that determines whether the project is successfully funded or not. Tomczak and Brem (2013) define the four models as:

1. All or nothing: If the pre-determined goal is not met, the funding project will be deemed unsuccessful and the money will be returned to the funders.

2. All and more: Even if the pre-determined goal is not met, the entrepreneur will receive the accumulated amount of money, at the cost of a higher platform fee for the entrepreneur.

3. Holding: The funder buys equity in a fund-seeking firm.

4. Club membership: The funder pays a fee to join a club, where experts invests or buys equity on behalf of others. This payout model exist to avoid legal issues, because equity crowdfunding are illegal in some countries.

\section{Motivators}

Research suggests that psychological motivations in an economical setting can be broadly divided in two sets of motivation drivers called intrinsic motivation and extrinsic motivation (Ryan \& Deci, 2000). Intrinsic motivation can be described as gaining satisfaction from the activity itself, whereas extrinsic motivation can be described as gaining satisfaction from the outcome of the activity. At the same time, many cases are more complex and a mix between intrinsic motivations and extrinsic motivations can be distinguished. A known issue when offering a choice between intrinsic and extrinsic motivations is the tendency of funders to choose extrinsic motivations before intrinsic motivation (Ryan \& Deci, 2000). Cholakova and Clarysse (2014) suggest that a combination of non-financial rewards, for example what we in this article call reward and pre-order, can be combined with financial rewards, as lending with interest and equity, without reducing the willingness of the funder to fund the non-financial objectives.

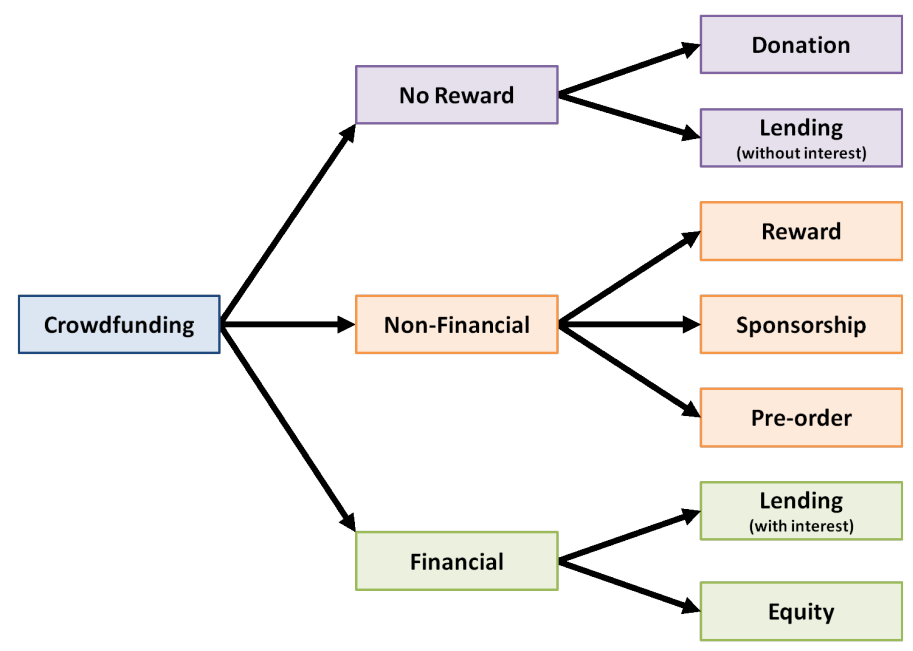

Figure 1. A three-category framework of the seven crowdfunding models

Gerber and Hui (2013) find that funders are motivated because of empathy for the project. Some funders wish to connect with others to satisfy a need for a feeling of belonging in a social context. Other funders feel a need to help the entrepreneur realize their goals (Gerber, Hui $\&$ Kuo, 2013). These motivators may be present in any model, but are particularly relevant with donations.

Another strong motivation for funders is desire to own the product itself or receive a tangible reward, what we here call pre-order and reward (Gerber \& Hui, 2013). In these cases, the funders are acting as consumers when backing a project (Belleflamme et al., 2014) and expect some form of return or reward (Belleflamme et al., 2013). In any case, the entrepreneur is driven to satisfy the felt need from the funders, because the goal for the entrepreneur is to fund his or her project (Gerber \& Hui, 2013).

Gerber and Hui (2013) suggest that one of the main deterrents for the funder is the distrust of the way the entrepreneur is going to use the funds, meaning that they worry that the entrepreneur is not going to fulfill the goals of the project and will just take the money for themselves. With the all-or-nothing model, the funder will only be forced to pay when and if the entrepreneur's project is successfully funded. The model prevents fraud within crowdfunding, both by not giving the entrepreneur any funds until the project is fully funded and the crowdfunding also binds the entrepreneur by a contract to deliver what they have promised. According to Tomczak and Brem (2013) the all-or-nothing model also works well for the entrepreneurs because 


\section{Crowdfunding: Finding the Optimal Platform for Funders and Entrepreneurs}

David Gedda, Billy Nilsson, Zebastian Såthén, and Klaus Solberg Søilen

they do not have to deliver on a promise they cannot keep without sufficient funding. This phenomena was earlier described by Kraut, Resnick, and Kiesler (2012) as "contingent commitment, wherein the willingness threshold for contributing is lowered because the investment will be completed only if the project is fully funded.

\section{Research Design and Methodology}

This study aims to find the best mix of crowdfunding and payout models for both funders and entrepreneurs. To achieve this aim, we evaluated previous research to find the models which were described earlier in the article. Tomczak and Brem's (2013) conceptual model is similar, but too comprehensive for the purpose of this study, which embraces the respondents' eventual lack of knowledge about the underlying components of crowdfunding. To our simplified version of Tomczak and Brem's (2013) model, we added lending.

\section{Crowdfunding platforms}

To relate our seven crowdfunding and four payout models to existing crowdfunding platforms, we used Alexa (alexa.com), a service that measures Internet traffic and rank websites. to identify the most visited crowdfunding platforms. Given that the focus of our research is on crowdfunded entrepreneurship, we excluded plat- forms that solely focused on charity. After the ranking of the 10 most visited sites used by entrepreneurs to crowdfund projects, we categorized them according to our seven crowdfunding and four payout models (Table $1)$.

\section{Development of the hypotheses}

Crowdfunding platforms are designed in different ways with different crowdfunding models and payout models. We want to determine if there is one or several platforms on the market that correspond with the wishes of the entrepreneurs, the funder, or preferably a combination of these. To examine this question, we have defined the following hypotheses:

\section{H1: The entrepreneurs' preferred combination of crowdfunding models and payout models are re- flected in one of the most visited crowdfunding platforms.}

H2: The funders' preferred combination of crowdfunding models and payout models are reflected in one of the most visited crowdfunding platforms.

H3: The entrepreneurs' and funders' preferred combination of crowdfunding models and payout model combined, is reflected in one of the most visited crowdfunding platforms.

Table 1. Crowdfunding and payout models of the 10 most visited crowdfunding platforms for entrepreneurs

\begin{tabular}{|c|c|c|c|c|c|c|c|c|c|}
\hline Platform & $\begin{array}{c}\text { Global } \\
\text { Alexa } \\
\text { Rank }\end{array}$ & Donation & Reward & Sponsoring & Pre-order & $\begin{array}{l}\text { Lending } \\
\text { without } \\
\text { Interest }\end{array}$ & $\begin{array}{l}\text { Lending } \\
\text { with } \\
\text { Interest }\end{array}$ & Equity & Payout Mode \\
\hline Kickstarter.com & 512 & $\mathrm{X}$ & $\mathrm{X}$ & $\mathrm{X}$ & $\mathrm{x}$ & & & & All or nothing \\
\hline Indiegogo.com & 1396 & $\mathrm{X}$ & $\mathrm{X}$ & $\mathrm{X}$ & $\mathrm{X}$ & & & & All and more \\
\hline Gofundme.com & 1446 & $\mathrm{X}$ & $\mathrm{X}$ & $\mathrm{X}$ & $\mathrm{X}$ & & & & All or nothing \\
\hline Teespring.com & 2077 & & & & $\mathrm{X}$ & & & & All or nothing \\
\hline Angel.co & 2373 & & & & & & & $\mathrm{X}$ & $\begin{array}{l}\text { Club } \\
\text { membership }\end{array}$ \\
\hline Patreon.com & 5310 & $\mathrm{X}$ & $\mathrm{X}$ & $\mathrm{X}$ & $\mathrm{X}$ & & & & All or nothing \\
\hline Lendingclub.com & 9582 & & & & & & $\mathrm{X}$ & & All and more \\
\hline Kiva.org & 12575 & & & & & $\mathrm{X}$ & & & All and more \\
\hline Pledgemusic.com & 27118 & & & $\mathrm{X}$ & $\mathrm{X}$ & & & & All or nothing \\
\hline Crowdfunder.com & 28178 & & & & & & & $\mathrm{X}$ & Holding \\
\hline
\end{tabular}




\title{
Crowdfunding: Finding the Optimal Platform for Funders and Entrepreneurs
}

\author{
David Gedda, Billy Nilsson, Zebastian Såthén, and Klaus Solberg Søilen
}

To find support for H3, it is important that there is support found for both $\mathrm{H} 1$ and $\mathrm{H} 2$, otherwise the optimal combination of both crowdfunding and payout models, for both entrepreneurs and funders does not exist, at the time when the study was conducted. By optimal, this study refers to one crowdfunding platform were the preferred combination of both crowdfunding and payout models of both entrepreneurs and funders are represented.

\section{Surveys of entrepreneurs and funders}

Two separate quantitative surveys of 18 entrepreneurs and 97 potential funders were conducted. Some items in the surveys were common, but others were tailored to funders or entrepreneurs. We based the surveys on our newly developed categorization of existing crowdfunding models and also included some items that can suggest further research. The respondents were asked to rank the payout and the crowdfunding models according to what they deem most attractive. The payout models are ranked from 1 to 4 and the crowdfunding models are ranked from 1 to 7 .

The survey was written in Swedish given that all respondents are native Swedish speakers. The funders were reached through personal networks. Schwienbacher \& Larralde (2010) describe the average funder as a white, married, middle-aged male in the middle to upper class with a university degree and high-speed Internet. Accordingly, we included questions about sex, age, income, education, civil status, and Internet connection. Race is not a commonly used distinction in Sweden, so we excluded questions relating to it. One other bias could be that funders that are not used to participate in crowdfunding initiatives may have a more extrinsic view, given that most people that are not used to using crowdfunding platforms, or even when using them for the first time tend to choose tangible rewards (Ryan \& Deci, 2000) , and most of our respondents probably have not participated in crowdfunding schemes before. We asked inexperienced participants for three reasons: i) crowdfunding was a new phenomena for Swedish people at the time of this study; ii) we wanted to receive views from funders that had not yet determined their preferred crowdfunding platform with a existing combination of crowdfunding and payout models; iii) an essential aspect of crowdfunding is that, regardless of background or experience, anyone can be a backer.

The entrepreneurs were reached through entrepreneurial hubs such as Science Park in Halmstad, Sweden, a centre gathering a large number of companies, and through the authors' personal networks. A web-survey reduced interference linked to having to answer the survey at a specific time and place, and also the presence of any of the authors in the room. The main problem of the survey was that crowdfunding is a rather unknown phenomenon, but by providing definitions of each crowdfunding and payout model, which made it clear to the respondents what the different definitions stood for, we reduced biases linked to lack of knowledge.

We selected entrepreneurs in the start-up phase, because that is the time the entrepreneurs are looking for low-level financing and turn to alternative investment mechanisms, such as crowdfunding platforms (Bradford, 2012). By contacting entrepreneurial hubs, we reached the target entrepreneurs easily. We did not select the sample for the funders in the same way as the sample for the entrepreneurs. By distributing the survey for the funders through the authors' social network contacts a wide target could be reached with variation in age, gender, ethnicity and occupation, although a majority of the respondents of this survey were students.

\section{Empirical Analysis and Discussion}

In this section, we summarize the data collected through the two different surveys as well as some brief observations made when conducting our categorization of the 10 most used crowdfunding platforms, as compiled using SurveyMonkey (surveymonkey.com). The ranking system is based on a 10-point scale where the highest average score is ranked as the favourite pick. The total score is presented in Tables 2 to 5 and in parenthesis after each of the mentioned models.

\section{Crowdfunding platforms}

Two clear, and quite important, observations were made when categorizing the crowdfunding platforms and their corresponding crowdfunding and payout models. First, if a platform offered any of the three crowdfunding models in the non-financial category, the other two also were represented. In the case of Teespring, the whole purpose of the site is to buy t-shirts; therefore, no reward or sponsorship opportunities were offered. PledgeMusic enables users to pre-purchase music that has not yet been created and, although they offer sponsorship, they do not offer a reward option. This observation led to the conclusion that the three non-financial crowdfunding models co-existed because funders tended to opt for extrinsic motivations, as suggested by Ryan and Deci (2000). But, because funders, as suggested by Mollick (2013), are heterogenous from 


\section{Crowdfunding: Finding the Optimal Platform for Funders and Entrepreneurs}

David Gedda, Billy Nilsson, Zebastian Såthén, and Klaus Solberg Søilen

case to case, and the sponsoring, reward, and pre-order crowdfunding models require different input of capital, where sponsoring requires the least amount of money, followed by reward and pre-order, all three models are needed when crowdfunding products. The second observation was that crowdfunding platforms only operate with one payout model; so, when suggesting the optimal crowdfunding platform for both funders and entrepreneurs. only one payout model will be possible.

\section{Entrepreneur preferences}

As presented in Table 2, sponsoring (5.06) was the favourite crowdfunding model selected by the entrepreneurs. Although donation (4.67) and pre-order (4.44) were picked by more entrepreneurs as their highest ranked choice, sponsoring gained a higher total score. The attraction to the sponsoring and donation crowdfunding models can be explained by the desire of entrepreneurs to seek the lowest cost of capital available (Belleflamme et al., 2014), given that donation gives funders nothing more than the intrinsic reward of feeling good about themselves (Ryan \& Deci, 2000) and sponsoring could take the form of a written thank you on the website of the funded project. The attraction to the pre-order crowdfunding model is that all projects on crowdfunding platforms have an actual product as their goal. This finding relates well to the need of funders to gain a tangible reward or the actual product itself and the entrepreneur's need to fill the funders' needs (Gerber \& Hui, 2013).
By applying the top picks from Table 2: sponsoring, donation, and pre-order, to the findings from Table 1 (crowdfunding models offered on the platforms), we see that the three most visited crowdfunding platforms offers the entrepreneurs' three most favoured crowdfunding models.

Entrepreneurs prefer the all-and-more payout model (3.17); almost half of the respondents picked it as their top choice, followed by the all-or-nothing model (2.72) (Table 3). This finding can be explained by the goal of entrepreneurs, which is mainly to raise money (Belleflamme et al., 2014), and the all-and-more model, as opposed to other payout models, lets the entrepreneur

Table 3. Entrepreneurs' ranked preferences for each payout model $(\mathrm{n}=18)$

\begin{tabular}{lccccc}
\hline & \multicolumn{5}{c}{ Rank } \\
Payout Model & $\mathbf{1}$ & $\mathbf{2}$ & $\mathbf{3}$ & $\mathbf{4}$ & Average \\
\hline All and more & 8 & 7 & 1 & 2 & 3.17 \\
\hline All or nothing & 6 & 5 & 3 & 4 & 2.72 \\
\hline Holding & 2 & 5 & 4 & 7 & 2.11 \\
\hline Club membership & 2 & 1 & 10 & 5 & 2.00 \\
\hline
\end{tabular}

Table 2. Entrepreneurs' ranked preferences for each crowdfunding model $(n=18)$

\begin{tabular}{lcccccccc}
\hline & \multicolumn{7}{c}{ Rank } & \\
Crowdfunding Model & $\mathbf{1}$ & $\mathbf{2}$ & $\mathbf{3}$ & $\mathbf{4}$ & $\mathbf{5}$ & $\mathbf{6}$ & $\mathbf{7}$ & Average \\
\hline Sponsorship & 2 & 6 & 2 & 7 & 1 & 0 & $\mathbf{0}$ & 5.06 \\
\hline Donation & 6 & 1 & 3 & 2 & 3 & 1 & 2 & 4.67 \\
\hline Pre-order & 4 & 1 & 5 & 1 & 4 & 2 & 1 & 4.44 \\
\hline Reward & 2 & 3 & 3 & 3 & 1 & 4 & 2 & 4.00 \\
\hline Equity & 2 & 2 & 4 & 3 & 3 & 1 & 3 & 4.00 \\
\hline Lending without interest & 1 & 4 & 1 & 2 & 4 & 6 & 0 & 3.78 \\
\hline Lending with interest & 1 & 1 & 0 & 0 & 2 & 4 & 10 & 2.06 \\
\hline
\end{tabular}




\section{Crowdfunding: Finding the Optimal Platform for Funders and Entrepreneurs}

David Gedda, Billy Nilsson, Zebastian Såthén, and Klaus Solberg Søilen

keep all the money they raise, minus the crowdfunding platform fees. (Tomzcak \& Brem, 2013). IndieGOGO was the second most visited crowdfunding platform, according to Alexa's Global Ranking system, and it offers the all-and-more model. According to Tomczak and Brem (2013), the all-or-nothing model also works well for entrepreneurs because they do not have to promise the funders something that they cannot deliver, which could explain the second-place finish of the all-or-nothing model. The low level of interest in the holding and club membership models may reflect the reluctance of entrepreneurs to give away the equity of their firms (4.00). By looking at the individual surveys, it was clear that entrepreneurs who chose investment as a top choice also selected holding or club membership as their preferred payout model. With the above discussion in mind, the suggested mix for entrepreneurs would be to use a platform that uses a mix of crowdfunding models and the payout model all and more, similar to the Indiegogo service, as described in Table 1.

Because the entrepreneurs' top picks of both crowdfunding and payout models were represented among the most popular crowdfunding platforms, our first hypothesis (H1) is supported by our findings: the entrepreneurs' favourite choices exist among the most popular platforms.

\section{Funder preferences}

According to the literature, one of the main goals of a funder is to support a project or help an entrepreneur to realize their project (Gerber et al., 2013). These intrinsic motivations (Ryan \& Deci, 2000), are not reflected in the findings of this study. The most picked choice, and the choice with the highest total score, was the equity option (4.86). To our knowledge, there is no theory supporting equity as a top choice of funders, which makes this an interesting discovery. Because equity crowdfunding is highly regulated by law, and for example, has not been available to American citizens until recently, this is a form of crowdfunding that rapidly is gaining in interest (Harrison, 2013). When compared to existing literature, the next four picks pre-order (4.54), sponsoring (4.13), reward (4.12), and donation (3.79) - were expected as the top choices with support from Gerber, Hui, and Kuo (2013).

For funders, a key consideration is the legitimacy of the entrepreneur (Gerber \& Hui, 2013). This perspective is represented by the top choice, all or nothing (2.8), among our funder respondents. The all-or-nothing model gives the funder the comfort of knowing that if the project is not successfully funded, the funder does not need to contribute any money to the project (Tomczak \& Brem, 2013). This concern may also explain why the all-and-more model (1.99) was the least favoured choice among our respondents. The second and third most favoured payout models, holding (2.69) and club membership (2.52), corresponds to the high interest of funders to buy equity in projects. When comparing the top pick from Table 5 with the top platforms' payout models from Table 1 it is clear that the all-or-nothing model is included among the most popular platforms.

Table 4. Funders' ranked preferences for each crowdfunding model $(n=97)$

\begin{tabular}{lcccccccc}
\hline & \multicolumn{7}{c}{ Rank } & \\
Crowdsourcing Model & $\mathbf{1}$ & $\mathbf{2}$ & $\mathbf{3}$ & $\mathbf{4}$ & $\mathbf{5}$ & $\mathbf{6}$ & $\mathbf{7}$ & Average \\
\hline Equity & 31 & 15 & 10 & 16 & 9 & 7 & 9 & 4.86 \\
\hline Pre-order & 20 & 12 & 18 & 18 & 12 & 13 & 4 & 4.54 \\
\hline Sponsorship & 9 & 17 & 13 & 26 & 13 & 9 & 10 & 4.13 \\
\hline Reward & 7 & 20 & 21 & 9 & 22 & 6 & 12 & 4.12 \\
\hline Donation & 13 & 9 & 16 & 13 & 14 & 17 & 15 & 3.79 \\
\hline Lending with interest & 8 & 16 & 10 & 7 & 12 & 21 & 23 & 3.41 \\
\hline Lending without interest & 9 & 8 & 9 & 8 & 15 & 24 & 24 & 3.14 \\
\hline
\end{tabular}

www.timreview.ca 


\section{Crowdfunding: Finding the Optimal Platform for Funders and Entrepreneurs}

\section{David Gedda, Billy Nilsson, Zebastian Såthén, and Klaus Solberg Søilen}

Table 5. Funders' ranked preferences for each payout model $(\mathrm{n}=97)$

\begin{tabular}{lccccc}
\hline \multicolumn{7}{c}{ Rank } \\
Payout Model & $\mathbf{1}$ & $\mathbf{2}$ & $\mathbf{3}$ & $\mathbf{4}$ & Average \\
\hline All or nothing & 33 & 26 & 24 & 14 & 2.80 \\
\hline Holding & 31 & 26 & 19 & 21 & 2.69 \\
\hline Club membership & 15 & 35 & 32 & 15 & 2.52 \\
\hline All and more & 18 & 10 & 22 & 47 & 1.99 \\
\hline
\end{tabular}

Because equity is not combined with the non-financial crowdfunding models among the 10 most popular platforms from Table 1, we do not have support for our second hypothesis (H2). In other words, the funders' optimal mix of crowdfunding and payout models are not represented among the crowdfunding platforms in Table 1 . This is a valuable discovery because it directs attention to an unexplored market opportunity.

\section{Combining the models}

To support our third hypothesis (H3), we would have needed support for both our first (H1) and second (H2) hypotheses. Given that support was not found for H2, we do not have support for H3 either. Because H1 was accepted, we conclude that crowdfunding platforms focus on sellers who, in the crowdfunding context are the entrepreneurs. Kickstarter is the most popular site

Table 6. Combined scores of entrepreneur and funder preferences for crowdfunding models

\begin{tabular}{lc}
\hline Crowdfunding Model & Combined Score \\
\hline Sponsorship & 9.19 \\
\hline Pre-order & 8.98 \\
\hline Equity & 8.86 \\
\hline Donation & 8.46 \\
\hline Reward & 8.12 \\
\hline Lending without interest & 6.92 \\
\hline Lending with interest & 5.47 \\
\hline
\end{tabular}

(Table 1), but many entrepreneurs must use a platform with a payout model they might not prefer, because they want to raise as much money from as many funders as possible (Gerber et al., 2013). Thus, in search of an optimal mix of crowdfunding and payout models, we added the average scores of entrepreneur (Table 2) and funder (Table 4) preferences for crowdfunding models and for payout models (Tables 3 and 5). The resulting combined scores are listed in Table 6 and Table 7 .

The optimal payout model for a crowdfunding platform, according to our data, would consist of a platform using the all-or-nothing payout model (5.52), which is found in most of the platforms in Table 1. Given that our investigated platforms only worked with one payout model per platform, and with the mindset that it is the funders that makes the entrepreneurs' projects possible, this choice seems logical. A new discovery from this study is that funders would like a combination between both non-financial and financial, in particular equity (4.86), crowdfunding models. None of the existing platforms in Table 1 offer this combination of crowdfunding models to its users. As mentioned in the observations made when categorizing the crowdfunding platforms, there is an underlying need for all three of the non-financial crowdfunding models to be present, because they require different amounts of capital; removing one might cause a potential funder not to back the project at all. Thus, we combine equity with all three of the non-financial crowdfunding models, and not only the top combined crowdfunding models. Even though it is stated in previous research that there may exist some dissonance when combining the intrinsic

Table 7. Combined scores of entrepreneur and funder preferences for crowdfunding models

\begin{tabular}{lc}
\hline Payout Model & Combined Score \\
\hline All or nothing & 5.52 \\
\hline All and more & 5.16 \\
\hline Holding & 4.80 \\
\hline Club membership & 4.52 \\
\hline
\end{tabular}




\title{
Crowdfunding: Finding the Optimal Platform for Funders and Entrepreneurs
}

\author{
David Gedda, Billy Nilsson, Zebastian Såthén, and Klaus Solberg Søilen
}

and extrinsic, where the extrinsic motivation can undermine the intrinsic (Ryan \& Deci, 2000), Cholakova and Clarysse (2014) suggest that funders are open to a crowdfunding platform that offers both financial and non-financial crowdfunding models, especially where the financial models influence the non-financial models in a positive way.

\section{Conclusion}

This article examined the favourite crowdfunding models and payout models of entrepreneurs and funders with the aim of finding if the optimal platform, in terms of these models, exists among the top 10 most visited crowdfunding platforms. To our knowledge this is the first article investigating both the entrepreneurs' and funders' points of view and proposing to combine them in search of an optimal model. The combination of the all-or-nothing payout model with both non-financial and equity crowdfunding models is what our findings points out as the optimal combination for both parts. The top 10 crowdfunding platforms are lacking in the funders' top choice, the equity model, in combination with the subsequent choices of pre-order, sponsoring, or reward. Our research also shows that the entrepreneurs' favourite models are represented in most visited crowdfunding platforms, at the time of the study. The results presented here can be of value for crowdfunding platforms, which can be designed according to an optimal combination of models. The results can help entrepreneurs choose which platform to use by providing information about which payout and crowdfunding models are preferred by funders, and therefore which platforms may improve their chances of successfully funding their projects.

Finally, we recommend the following future directions of study:

1. Carry out a study with a bigger sample, given that the survey made for this article had a limited number of respondents. A bigger survey is needed to strengthen the reliability of the results, particularly across different cultures.

2. Further investigate why the most popular crowdfunding platforms have not yet combined the equity model with other non-financial crowdfunding models, which suggests an asymmetry between funders and entrepreneurs. Crowdfunding platforms that are combining both financial and non-financial crowdfunding models were available on the market at the time of the study, but are not represented in the list of the most popular platforms. Future research should attempt to better understand these findings.

3. Study and introduce a third party in this ecosystem, namely the crowdfunding platforms themselves, which may reveal an optimal combination that reflects these three different interests.

4. Introduce a longitudinal aspect to the study, which will help grasp the evolution of the platforms and crowdfunding models over time.

\section{About the Authors}

David Gedda is a Master's student with a specialization in Marketing at Halmstad University, Sweden,. His research interests include crowdfunding platforms for entrepreneurs and corporate management success factors in a business-to-business context. Alongside his studies, he works in sales.

Billy Nilsson is a Master's student with a specialization in Marketing at Halmstad University, Sweden, where he is currently writing his thesis on competitive intelligence on Web 2.0 platforms. He is also a touring musician in the band Strucky Likes, a partner in the record label VÅRØ, and a concert promoter at Tillsammans Sessions.

Zebastian Såthén is a Master's student with a specialization in Marketing at Halmstad University, Sweden, where he is also studying to become a real estate agent. He currently works as a real estate assistant in his hometown of Smögen.

Klaus Solberg Søilen is Professor of Management at Halmstad University, Sweden. He is the Editor-inChief of the Journal of Intelligence Studies in Business (JISIB) and Senior Editor of the International Journal of Innovation Science (IJIS). He has published half a dozen books and more than thirty scientific articles on a wide area of management and marketing topics. 


\section{Crowdfunding: Finding the Optimal Platform for Funders and Entrepreneurs}

David Gedda, Billy Nilsson, Zebastian Såthén, and Klaus Solberg Søilen

\section{References}

Belleflamme, P., Lambert, T., \& Schwienbacher, A. 2014. Crowdfunding: Tapping the Right Crowd. Journal of Business Venturing, 29(5): 585-609.

http://dx.doi.org/10.1016/j.jbusvent.2013.07.003

Alexa. 2014. The Top Sites on the Web (Global). Alexa. Accessed November 14, 2014:

http://www.alexa.com/topsites

Belleflamme, P., Lambert, T., \& Schwienbacher, A. 2013. Individual Crowdfunding Practises. Venture Capital, 15(4):313-333. http://dx.doi.org/10.1080/13691066.2013.785151

Bradford, C. S. 2012. Crowdfunding and the Federal Securities Laws. Columbia Business Law Review, 1: 1-150.

Cholakova, M., \& Clarysse, B. 2014. Does the Possibility to Make Equity Investments in Crowdfunding Projects Crowd Out RewardBased Investments? Entrepreneurship Theory and Practise, 39(1): 145-172. http://dx.doi.org/10.1111/etap.12139

Collins, L., \& Pierrakis, Y. 2012. The Venture Crowd: Crowdfunding Equity Investment into Business. London: Nesta.

Gerber, E., \& Hui, J. S. 2013. Crowdfunding: Motivations and Deterrents for Participation. ACM Transactions on ComputerHuman Interaction (TOCHI), 20(6): Article 34. http://dx.doi.org/10.1145/2530540

Gerber, E., Hui, J. S., \& Kuo, P. -Y. 2013. Crowdfunding: Why People Are Motivated to Post and Fund Projects on Crowdfunding Platforms. Paper presented at the 2012 ACM Conference on Computer Supported Cooperative Work: International Workshop on Design, Influence, and Social Technologies: Techniques, Impacts and Ethics.
Harrison, R. 2013. Crowdfunding and the Revitalisation of the Early Stage Risk Capital Market: Catalyst or Chimera? Venture Capital, 15(4): 283-287.

http://dx.doi.org/10.1080/13691066.2013.852331

Hemer, J. 2011. A Snapshot on Crowdfunding. Working Papers Firms and Region, No R2/2011. Fraunhofer Institute for Systems and Innovation Research ISI. http://hdl.handle.net/10419/52302

Kraut, R. E., Resnick, P., \& Kiesler, S. 2012. Building Successful Online Communities: Evidence-Based Social Design. Cambridge, MA: The MIT Press.

Lehner, O. M. 2013 Crowdfunding Social Ventures: A Model and Research Agenda. Venture Capital, 15(4): 289-311. http://dx.doi.org/10.1080/13691066.2013.782624

Mollick, E. R. 2013. The Dynamics of Crowdfunding: An Exploratory Study. Journal of Business Venturing, 29(1): 1-16. http://dx.doi.org/10.1016/j.jbusvent.2013.06.005

Ryan, R. M., \& Deci, E. L. 2000. Intrinsic and Extrinsic Motivations: Classic Definitions and New Directions. Contemporary Educational Psychology, 25(1): 54-67. http://dx.doi.org/10.1006/ceps.1999.1020

Schwienbacher, A., \& Larralde, B. 2010. Crowdfunding of Small Entrepreneurial Ventures. Handbook of Entrepreneurial Finance. Oxford: Oxford University Press.

Tech, R. P. G. 2014. Crowdfunding Hardware Startups in Germany. In Proceedings of the European Conference on Information Systems (ECIS) 2014, Tel Aviv, Israel, June 9-11, 2014.

Tomczak, A., \& Brem, A. 2013. A Conceptualized Investment Model of Crowdfunding. Venture Capital, 15(4): 335-359. http://dx.doi.org/10.1080/13691066.2013.847614

Citation: Gedda, D., Nilsson, D., Såthén, Z., \& Solberg Søilen, K. 2016. Crowdfunding: Finding the Optimal Platform for Funders and

Entrepreneurs. Technology Innovation Management Review, 6(3): 31-40. http://timreview.ca/article/973 